\title{
FRICTION AND WEAR BEHAVIOR OF DISC BRAKE PAD MATERIAL USING BANANA PEEL POWDER
}

\author{
Masrat Bashir ${ }^{1}$, Sheikh Shahid Saleem ${ }^{2}$, Owais Bashir ${ }^{3}$ \\ ${ }^{l}$ M.Tech, National Institute of Technology, Srinagar, India \\ ${ }^{2}$ Associate Professor, Mechanical Engineering Department, National Institute of Technology, Srinagar, India \\ ${ }^{3}$ B.E, University of Kashmir, Srinagar, India
}

\begin{abstract}
Brake Pad material is a heterogeneous material and is composed of a few elements and each element has its own function. The ideal brake material should have constant coefficient of friction under various operating conditions such as applied loads, temperature, speeds and mode of braking. During adverse braking conditions excessive frictional heat is generated which results in the drop of coefficient of friction of the brake pad material. This drop in coefficient of friction is due to the degradation of resin which is associated with the loos of its binding ability. In order to maintain constant coefficient of friction at higher temperature new brake pad material has been formulated which retains the binding ability of the resin. The formulation of new brake pad material includes four friction composites containing 13 ingredients including phenolic resin and banana peel powder as a modified binder. A reciprocating friction monitor is used to carry friction and wear tests. Three tests via $t_{1}, t_{2}$ and $t_{3}$ with different loads and temperatures were conducted for duration of 10 minutes. The results showed that the coefficient of friction increased at higher temperature and friction and wear characteristics indicate that banana peel powder can be effectively used to increase the binding ability of phenolic resin at higher temperature.
\end{abstract}

Keywords: Brake pad; Banana peel powder; Phenolic resin; Friction; Wear

\section{INTRODUCTION}

The brake system is a very important component of vehicles and machinery equipment in industries. The brake system calls for more efficient brakes as compared to the brake systems employed in older days when maximum speed was much less as compared to the fast running vehicles manufactured now a days. Today, most vehicles use disc brakes as they dissipate heat better, hence reducing fade when compared to drum brakes [1]. The rotor disc materials of a disc brake system are normally made from gray cast iron, due to its excellent heat conductivity, good damping capacity and high strength [1-3]. Brakes must not only stop the moving vehicle but stop it in the shortest possible distance. The ability of a braking system to provide safe, repeatable stopping is the key to safe motoring.

The formulation of a brake pad material requires the optimization of multiple performance criteria. The brake pad material should achieve a stable and adequate coefficient of friction $(\mu)$ and should produce low fade and low wear. Resin is one of the most important ingredients of brake pad material because it binds all the other ingredients firmly and allows them to contribute effectively to the desired performance. However, when excessive frictional heat is generated during adverse braking, performance of the brake pad material deteriorates. This drop in performance may be related to the degradation of resin which is associated with loss of its binding ability. Therefore the brake pad material's thermal stability, its ability to retain mechanical properties, and its ability to bind its ingredients together under adverse braking conditions all depend on the resin [4].
The current work investigates the characteristics of modified binder on the friction and wear of disc brake pad material. In order to prevent the drop in performance due to the reduced binding ability of resin at higher temperature, banana peel powder, which acts as a modified binder, is used along with the phenolic resin During the study of the physiochemical properties of banana peel, it was observed that banana peel consists of higher content of antioxidant compounds and pectin [5]. Pectin substances are complex mixtures of polysaccharides containing units of galacturonic acid as the main chain which acts as a gelling agent. The hardness of the substance increases with the addition of banana peel powder. It was also observed that on increasing the temperature, the banana peel powder becomes more gelatinous and at much higher temperatures it becomes hard $[6,7]$. Because of these properties of banana peel, it is used in the formulation of new brake pad material to increase the binding ability of resin at higher temperatures. Therefore, four friction composites containing 13 ingredients along with phenolic resin and with banana peel powder as a modified binder in nine different concentrations by weight are formulated and evaluated for tribological properties. The effects of load, frequency and temperature on surface characteristics and friction are evaluated.

\section{EXPERIMENTATION}

\subsection{Fabrication of the Composites}

Frictional material is a heterogeneous material and is composed of few elements; each element has its own function. Changes in the element types or weight percentage of the elements in the formulation may change the physical, 
chemical and mechanical properties of the brake friction material $[8,9]$. Brake pad material typically comprises the following sub-components:

(i) Fillers, improve manufacturability, (ii) Friction Modifiers, act as lubricants, modifies wear and friction coefficient, (iii) Reinforcements, provides mechanical strength and (iv) Binder Materials, maintain structural integrity. In this work, ten new friction material formulations which are composed of thirteen elements have been developed using Power Metallurgy technique. The size of powders used, are in the range of $50 \mu \mathrm{m}-100 \mu \mathrm{m}$ and the fibers have length ranging from $0.97 \mathrm{~mm}-1.75 \mathrm{~mm}$. The basic composition of the Disc Brake Pad Material is shown in the Chart-1.

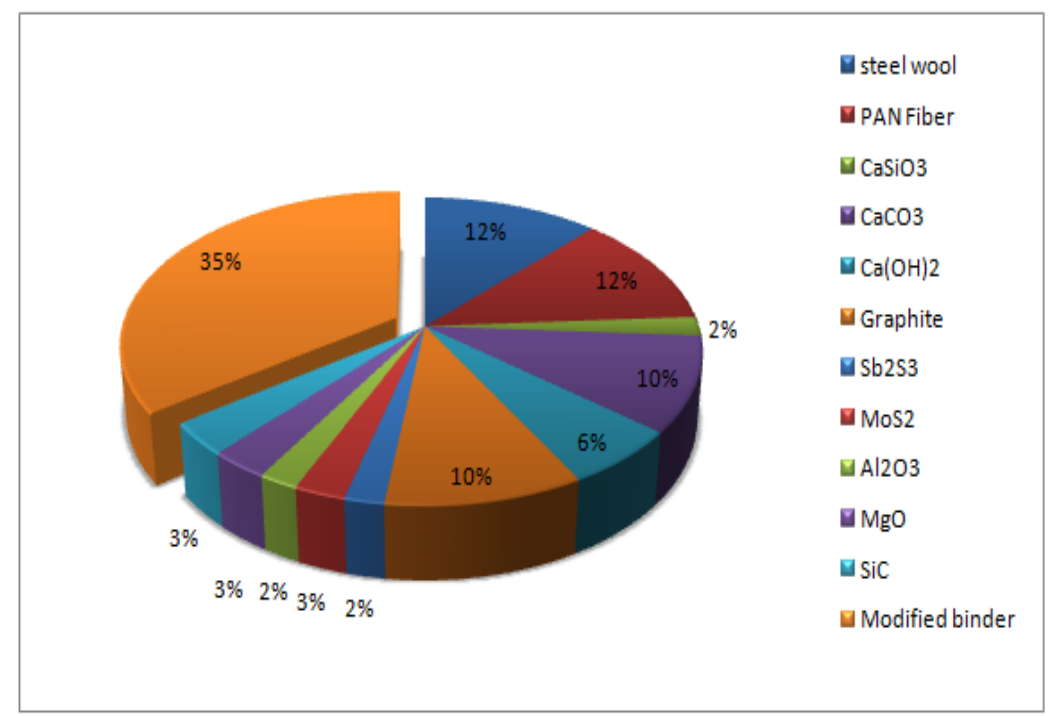

Chart-1: Composition of the Disc Brake Pad Material used in the designed sample.

The fabrication of composites containing thirteen ingredients is based on keeping parent composition of 11 ingredients (65 wt.\%) constant and varying two ingredients, viz. phenolic resin and banana peel (modified binder - 35 wt. \%) in complementary manner as shown in Chart-2. Based on a systematic increase in banana peel powder, ten samples A-J are formulated. (See Table-1).

The ingredients are mixed using an organic solvent ethanol, in a beaker to ensure the macroscopic homogeneity. The beaker is kept on a magnetic stirrer. The addition of ingredients during mixing is done in a particular sequence. First Powdery materials are mixed for 5 minutes followed by PAN fiber. After taking off the beaker from magnetic, stirrer, steel wool is added. The mixing schedule is of twenty minute duration. The mixing sequence and time of mixing of each lot of ingredients lead to proper uniformity in the mixture. The mixture is then placed in an oven for half an hour to evaporate the organic solvent and get a homogenous powder mixture.

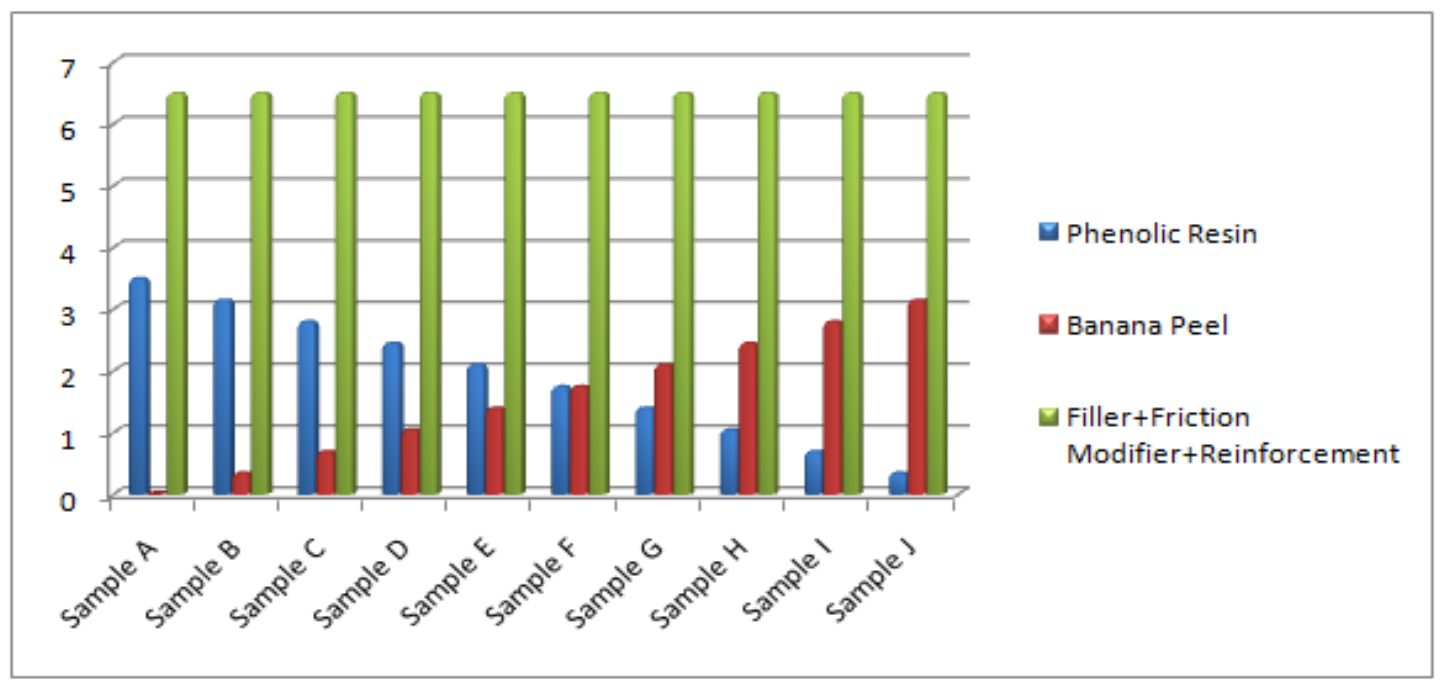

Chart-2: Varying amount of Phenolic Resin and Banana Peel used in designed sample. 
Table-1: Relative content of raw materials in the designed samples.

\begin{tabular}{|c|c|c|c|c|c|c|c|c|c|c|c|}
\hline Function & $\begin{array}{c}\text { Raw material } \\
\text { (wt. \%) }\end{array}$ & A & B & C & D & $\mathbf{E}$ & $\mathbf{F}$ & G & $\mathbf{H}$ & I & $\mathbf{J}$ \\
\hline \multirow{2}{*}{ Modified Binder } & Phenolic Resin & 35 & 31.5 & 28 & 24.5 & 21 & 17.5 & 14 & 10.5 & 7 & 3.5 \\
\hline & Banana peel & 0 & 3.5 & 7 & 10.5 & 14 & 17.5 & 21 & 24.5 & 28 & 31.5 \\
\hline \multirow{2}{*}{ Filler } & $\mathrm{CaCO}_{3}$ & 10 & 10 & 10 & 10 & 10 & 10 & 10 & 10 & 10 & 10 \\
\hline & $\mathrm{Ca}(\mathrm{OH})_{2}$ & 6 & 6 & 6 & 6 & 6 & 6 & 6 & 6 & 6 & 6 \\
\hline \multirow{6}{*}{ Friction Modifiers } & Graphite & 10 & 10 & 10 & 10 & 10 & 10 & 10 & 10 & 10 & 10 \\
\hline & $\mathrm{Sb}_{2} \mathrm{~S}_{3}$ & 2 & 2 & 2 & 2 & 2 & 2 & 2 & 2 & 2 & 2 \\
\hline & $\mathrm{MoS}_{2}$ & 2.6 & 2.6 & 2.6 & 2.6 & 2.6 & 2.6 & 2.6 & 2.6 & 2.6 & 2.6 \\
\hline & $\mathrm{Al}_{2} \mathrm{O}_{3}$ & 2 & 2 & 2 & 2 & 2 & 2 & 2 & 2 & 2 & 2 \\
\hline & $\mathrm{MgO}$ & 3 & 3 & 3 & 3 & 3 & 3 & 3 & 3 & 3 & 3 \\
\hline & $\mathrm{SiC}$ & 3.4 & 3.4 & 3.4 & 3.4 & 3.4 & 3.4 & 3.4 & 3.4 & 3.4 & 3.4 \\
\hline \multirow{3}{*}{ Reinforcement } & Steel wool & 12 & 12 & 12 & 12 & 12 & 12 & 12 & 12 & 12 & 12 \\
\hline & PAN fiber & 12 & 12 & 12 & 12 & 12 & 12 & 12 & 12 & 12 & 12 \\
\hline & $\mathrm{CaSiO}_{3}$ & 2 & 2 & 2 & 2 & 2 & 2 & 2 & 2 & 2 & 2 \\
\hline
\end{tabular}

Immediately after a homogenous mixture is obtained, it is poured into the cleaned die for hot compaction. The main purpose of the compaction process using hydraulic press is to obtain the compacts of desired shape with sufficient strength. The die is filled with approximately $10 \mathrm{~g}$ of the mixture of ingredients and heat cured under a pressure of $15 \mathrm{MPa}$ and $150{ }^{\circ} \mathrm{C}$ temperature for 10 minutes. During the compaction process, three intermittent "breathings" are also allowed to expel volatiles. When the compaction process is completed, the die is allowed to cool to remove the prepared samples.
The samples prepared in the hydraulic press are post cured in a muffle furnace at $100{ }^{\circ} \mathrm{C}$ for 8 hours. The post curing operation is done to cure the residual resin [4]. Therefore, the required samples $\mathrm{A}, \mathrm{B}, \mathrm{C}, \mathrm{D}, \mathrm{E}, \mathrm{F}, \mathrm{G}, \mathrm{H}, \mathrm{I}$ and $\mathrm{J}$ are prepared. Once the samples of appropriate size and shape have been prepared, they are ready for polishing. Polishing of the samples is done on a fixed speed manually operated machine. Samples are manually held as they are ground and polished on interchangeable fixed abrasive paper up to 1000 grits. Therefore the final samples of $32 \mathrm{~mm}$ diameter are ready for testing, shown in Fig-1.

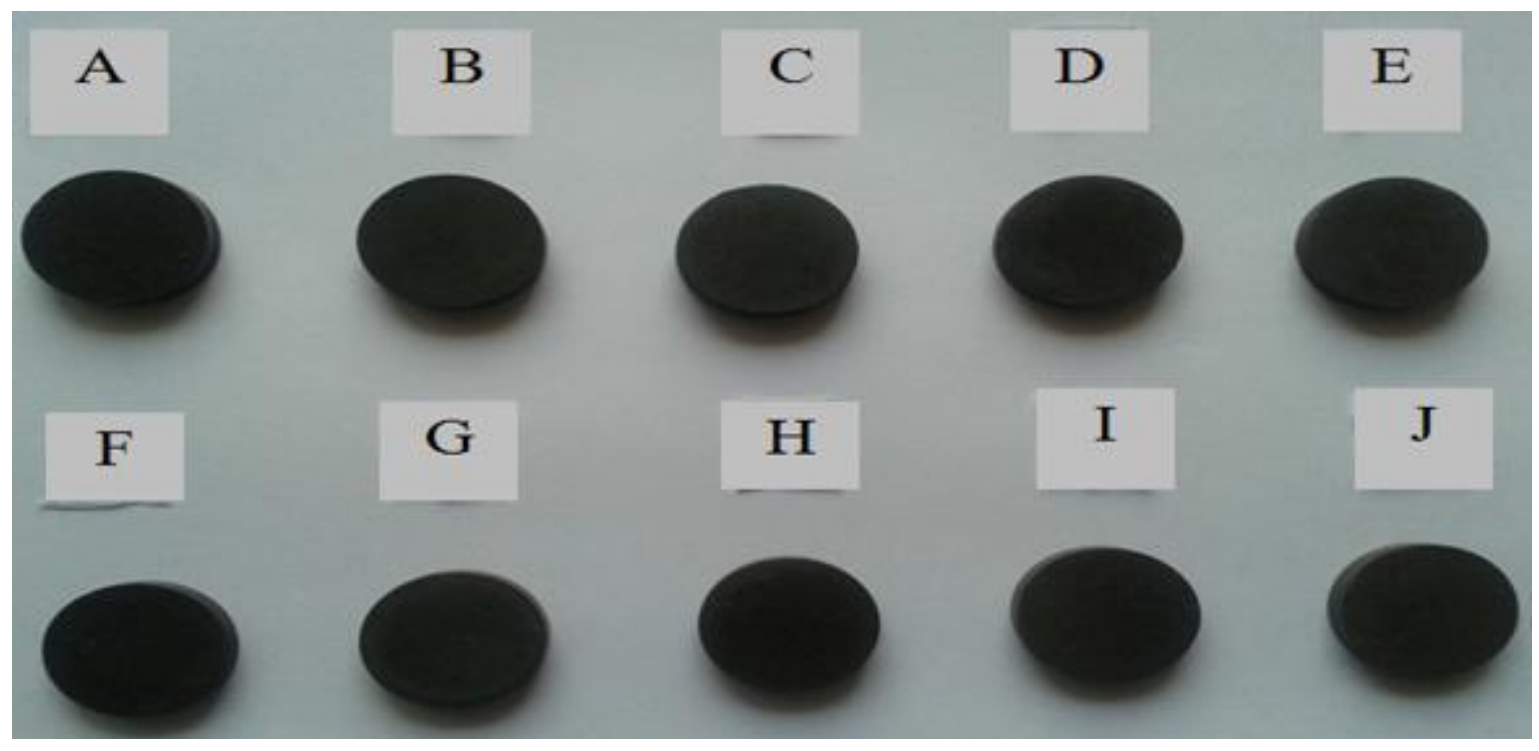

Fig-1: Disc Brake Pad samples of varying composition. 


\subsection{Friction and Wear Tests}

The objective of the experimental research presented in this paper is to establish the general behavior of the newly developed friction material as a light weight automotive brake pad when it is subjected to significant compression loads and high temperature. Friction and wear tests were performed on a reciprocating friction monitor, which is a versatile, digitally controlled machine for evaluation of friction and wear properties of the material under dry and lubricated conditions. In this machine, the oscillating motion is provided by a controlled variable speed AC Servo motor, the motor speed is controlled through an eccentric scotch yoke mechanism for the adjustment of the stroke. Test frequency, stroke, load, temperature and duration of test are preset. Friction force is measured continually by a piezoelectric transducer. The friction coefficient is also automatically calculated and recorded throughout the test through the data acquisition software. However the method employed for wear measurement is the weight loss method [10].

In the present experiment, the new set of disc with $14 \mathrm{~mm}$ diameter was specially designed and fabricated to be suitable for area contact testing. The disc is employed as an upper specimen and the brake pad material as a lower specimen. The upper specimen is placed into the holder and then clamped by screws. The lower specimen is mounted on a stainless steel heater block and fastened firmly by two screws to the framework shown in Fig-2.

Table -2: Friction test data for brake pad samples.

\begin{tabular}{|c|c|c|c|c|c|}
\hline Test & $\begin{array}{c}\text { Freq- } \\
\text { uency } \\
(\mathrm{Hz})\end{array}$ & $\begin{array}{c}\text { Stroke } \\
(\mathrm{mm})\end{array}$ & $\begin{array}{c}\text { Load } \\
(\mathrm{N})\end{array}$ & $\begin{array}{c}\text { Temp. } \\
\left({ }^{0} \mathrm{C}\right)\end{array}$ & $\begin{array}{c}\text { Duration } \\
(\mathrm{min})\end{array}$ \\
\hline $\mathrm{t}_{1}$ & 40 & 2 & 60 & 150 & 10 \\
\hline $\mathrm{t}_{2}$ & 40 & 2 & 120 & 250 & 10 \\
\hline $\mathrm{t}_{3}$ & 40 & 2 & 180 & 350 & 10 \\
\hline
\end{tabular}

Three tests were conducted on each sample which are defined according to the increased severity of braking conditions. These tests correspond to low $\left(t_{1}\right)$, medium $\left(t_{2}\right)$ and high $\left(t_{3}\right)$ energy tests shown in Table 2. In all cases, frequency, stroke and duration of the tests were kept constant. After every test the upper and lower specimen needs to be renewed.

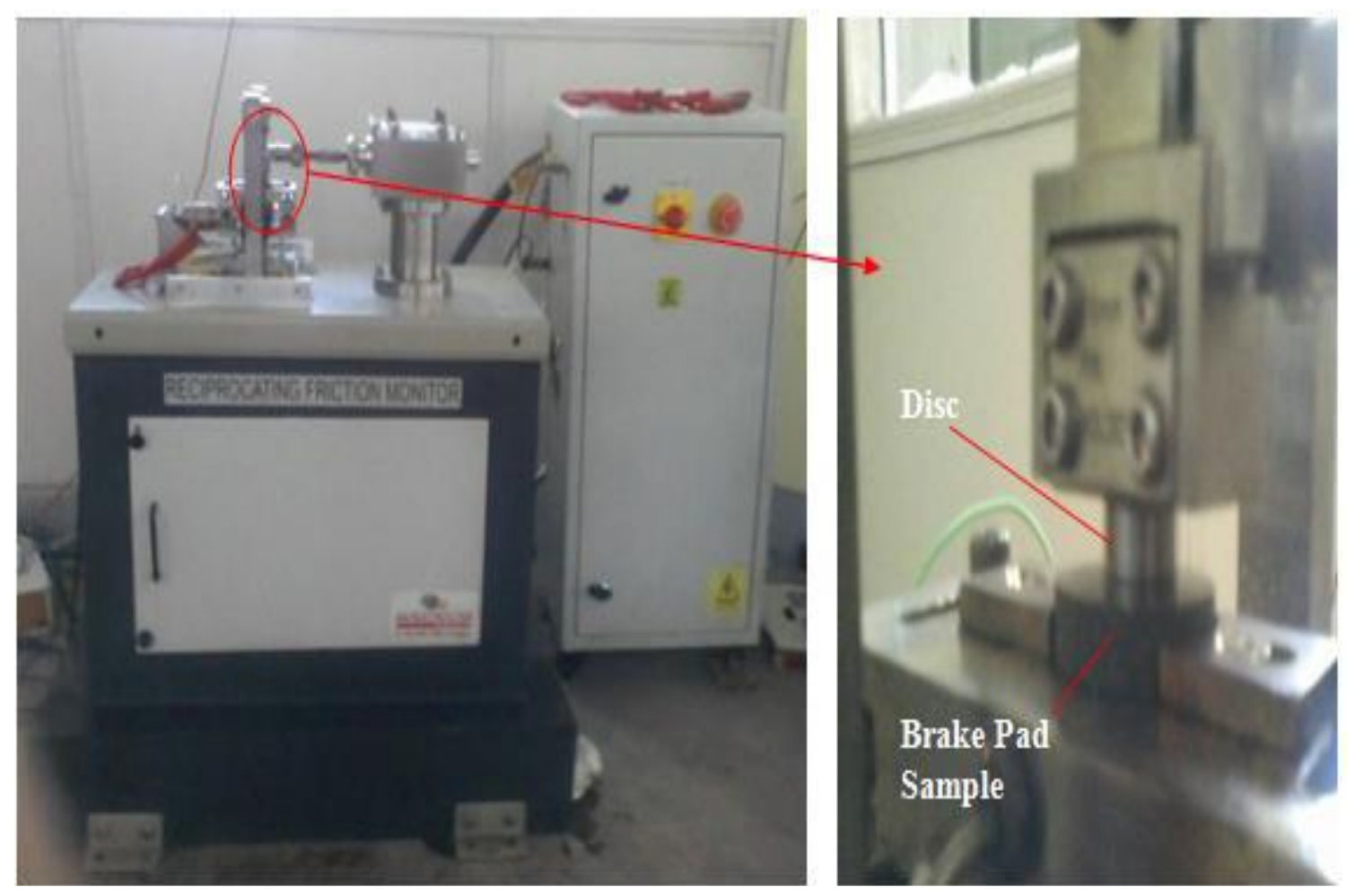

(a)

(b)

Fig.-2: (a) Reciprocating Friction Monitor (b) Designed disc and sample in contact. 
The various steps involved for conducting the friction and wear tests of the samples on the reciprocating friction monitor are as follows:

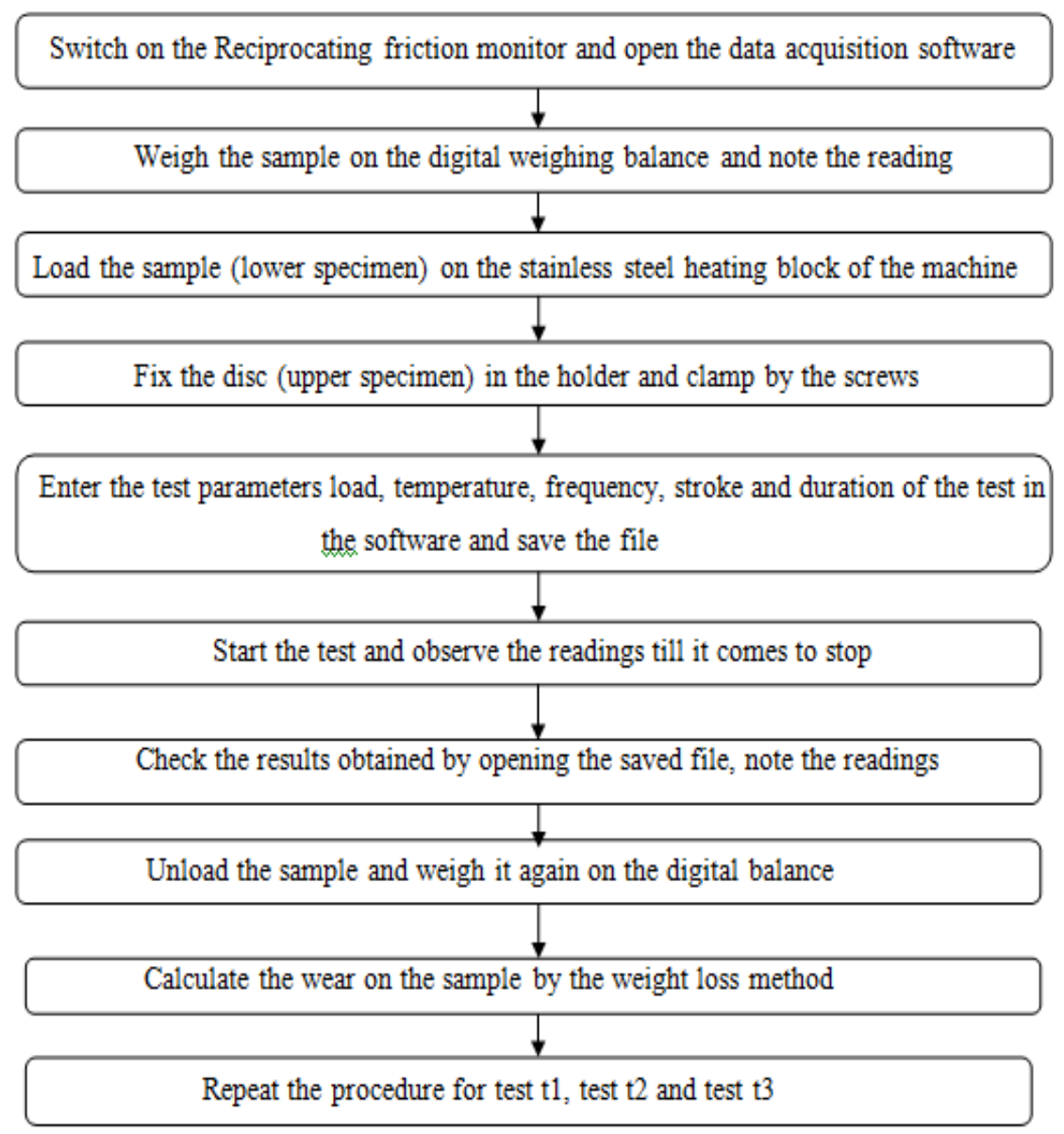

Same procedure is followed for the ten samples A-J and the values of coefficient of friction and wear are recorded after every cycle of the braking test, in a synchronized manner.

\section{RESULTS AND DISCUSSION}

Fig. 3 \& Fig. 12 shows the coefficient of friction of ten samples (A-J) for test $t_{1}, t_{2} \& t_{3}$.

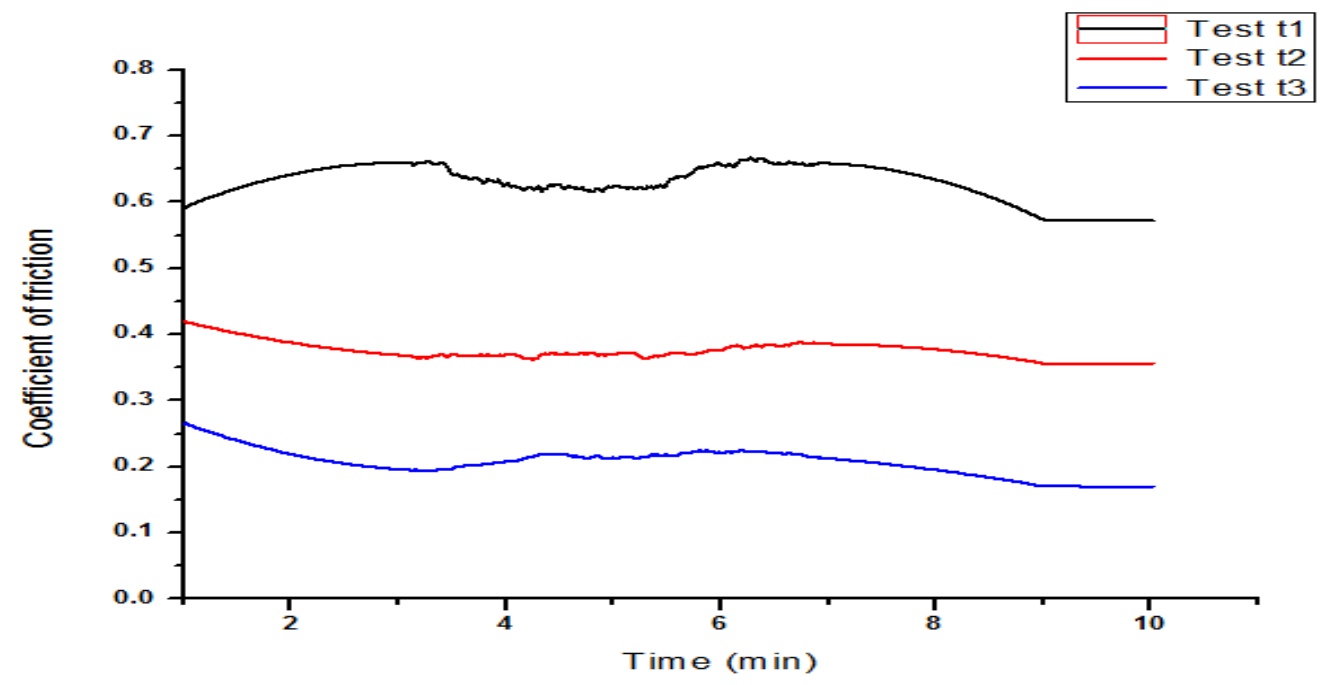

Fig.-3: Coefficient of friction for test $\left(t_{1}\right)$, test $\left(t_{2}\right)$ and test $\left(t_{3}\right)$ of sample A. 


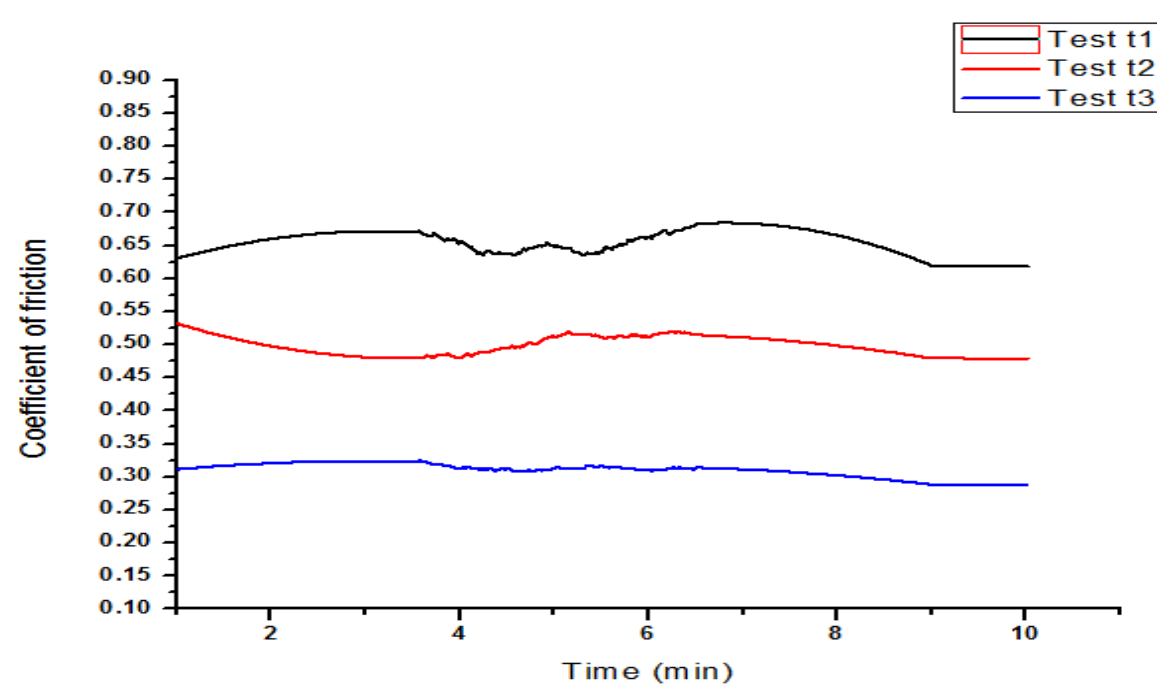

Fig.-4: Coefficient of friction for test $\left(\mathrm{t}_{1}\right)$, test $\left(\mathrm{t}_{2}\right)$ and test $\left(\mathrm{t}_{3}\right)$ of sample $\mathrm{B}$.

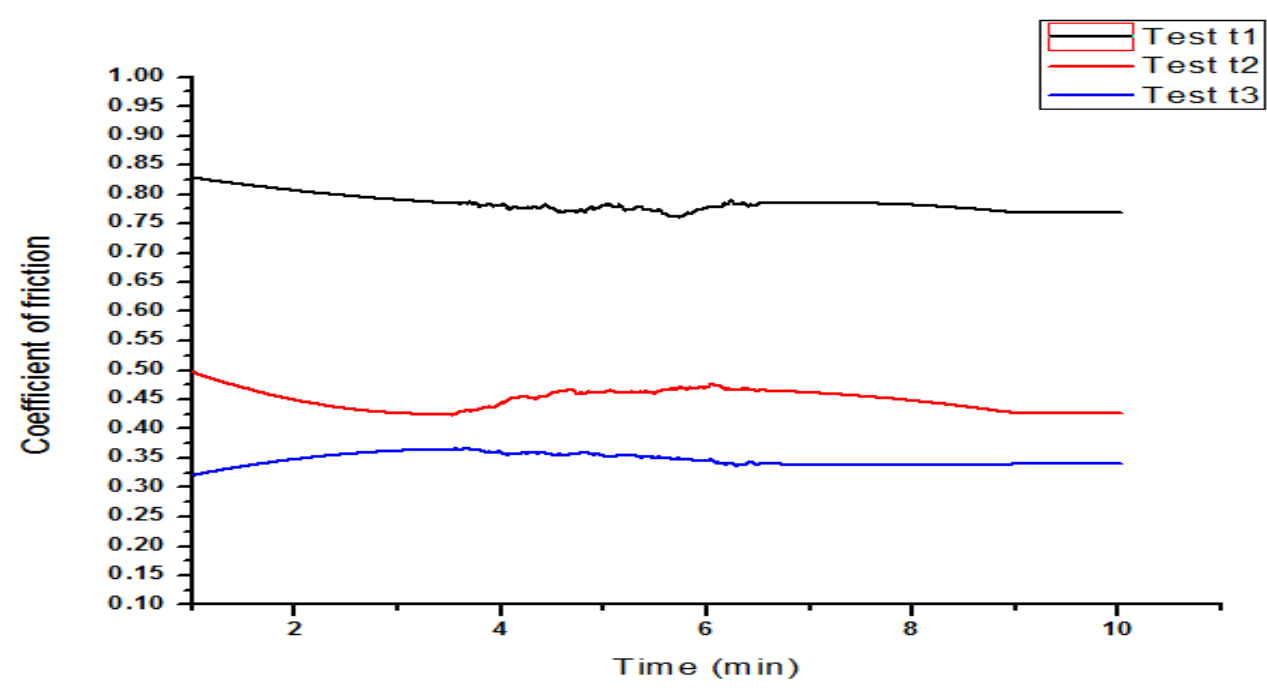

Fig.-5: Coefficient of friction for test $\left(t_{1}\right)$, test $\left(t_{2}\right)$ and test $\left(t_{3}\right)$ of sample $C$.

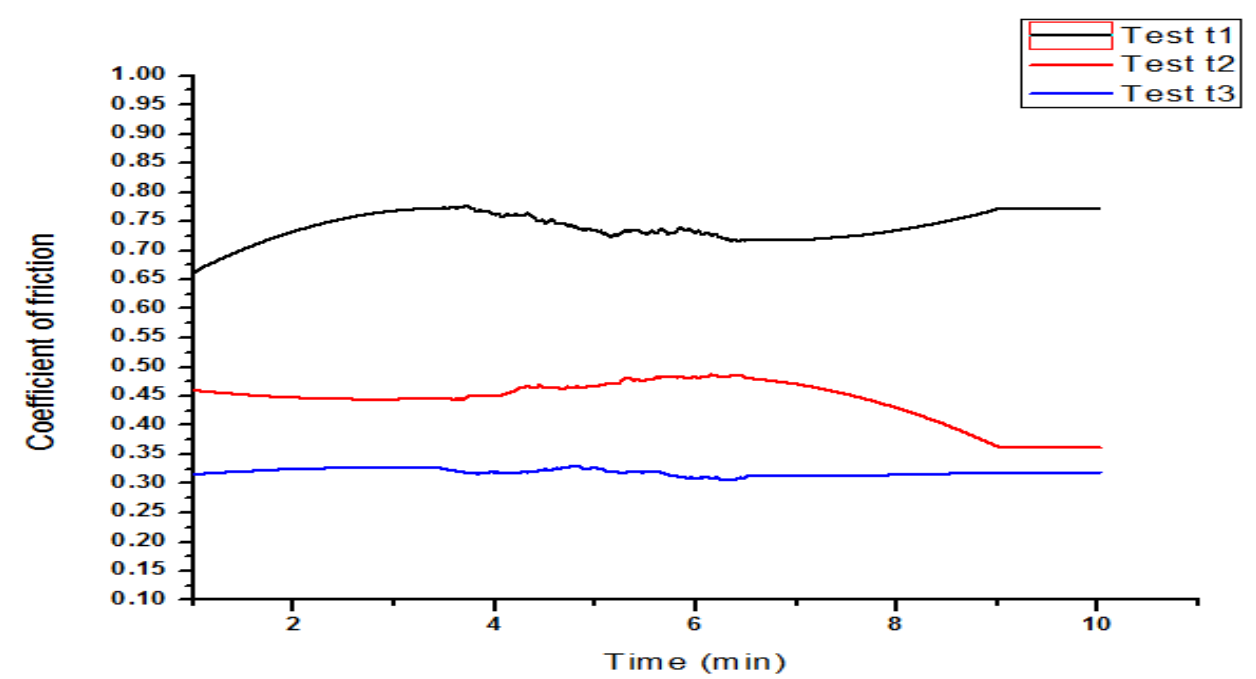

Fig.-6: Coefficient of friction for test $\left(t_{1}\right)$, test $\left(t_{2}\right)$ and test $\left(t_{3}\right)$ of sample D. 


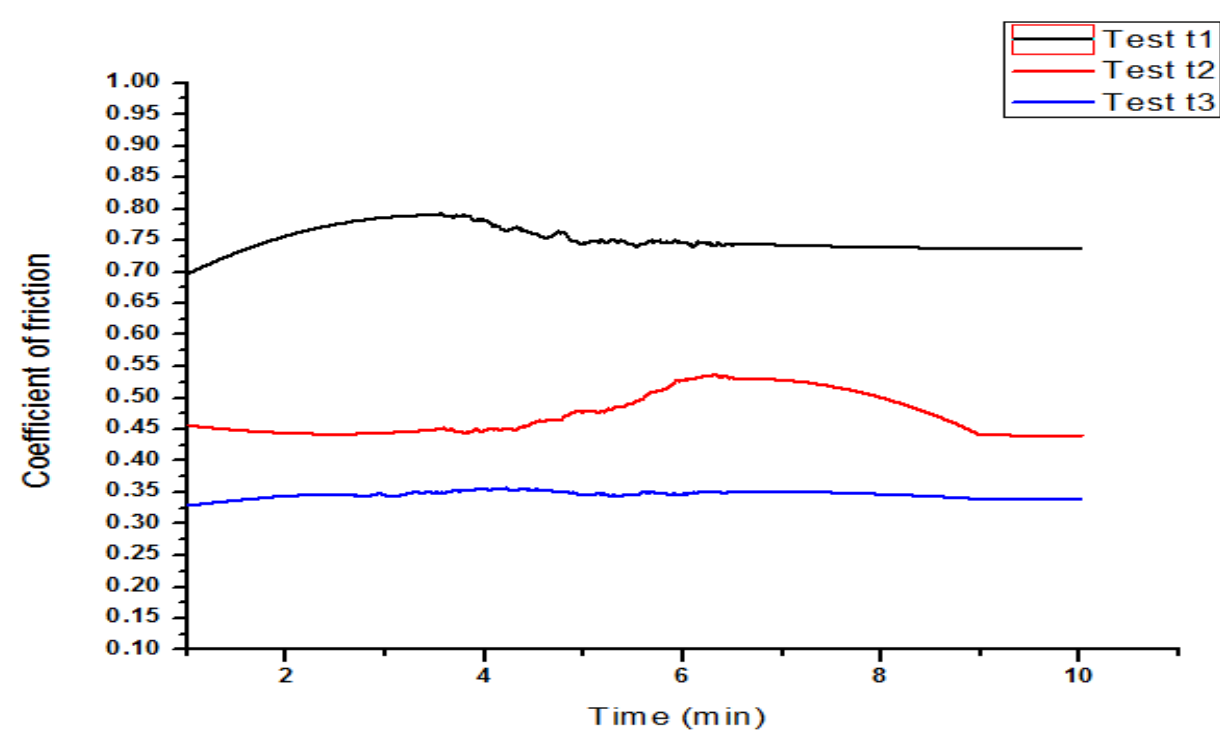

Fig.-7: Coefficient of friction for test $\left(t_{1}\right)$, test $\left(t_{2}\right)$ and test $\left(t_{3}\right)$ of sample $E$.

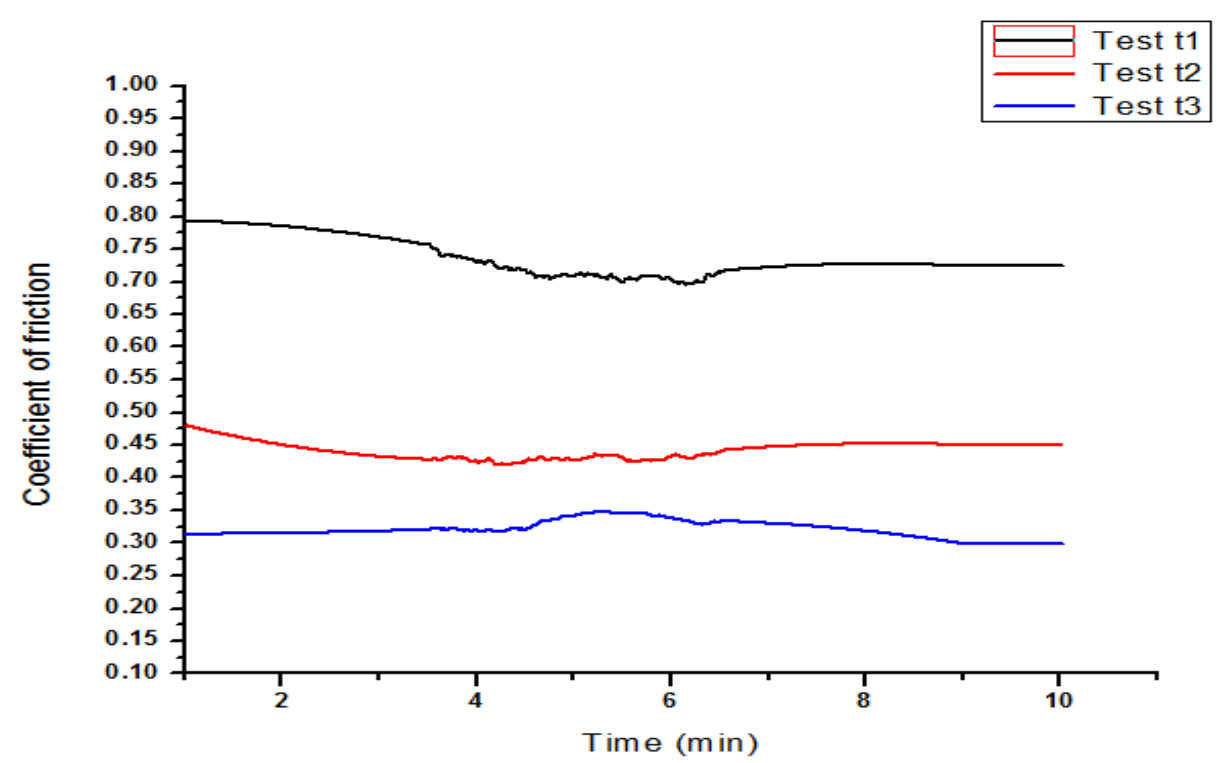

Fig.-8: Coefficient of friction for test $\left(\mathrm{t}_{1}\right)$, test $\left(\mathrm{t}_{2}\right)$ and test $\left(\mathrm{t}_{3}\right)$ of sample $\mathrm{F}$.

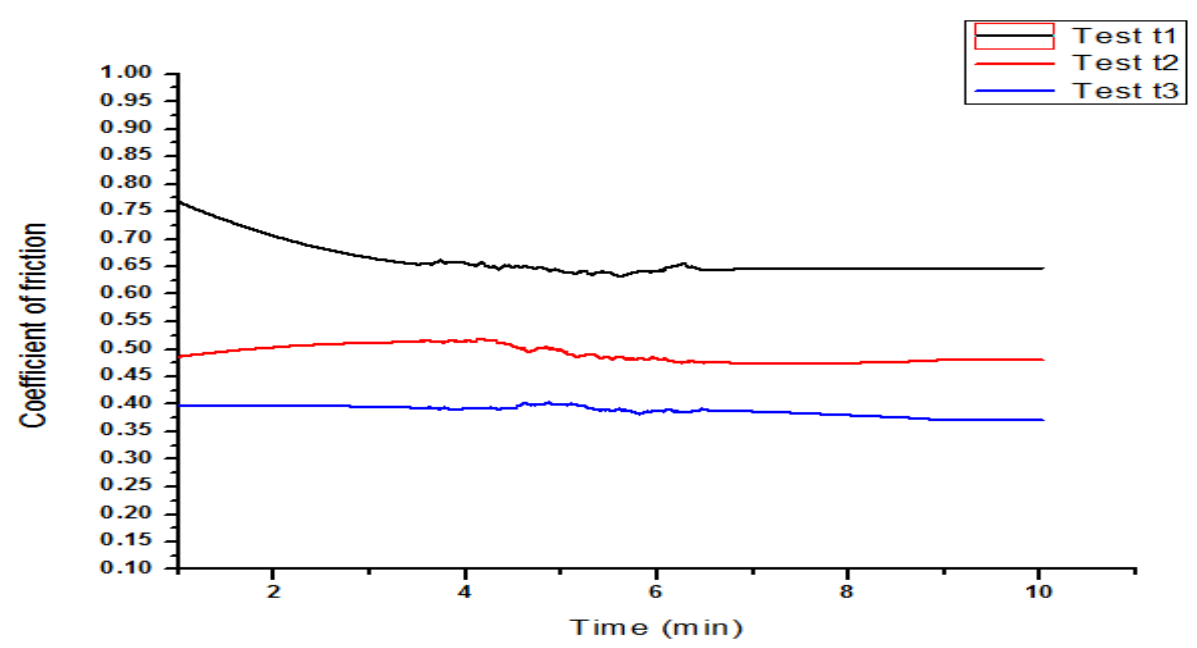

Fig.-9: Coefficient of friction for test $\left(t_{1}\right)$, test $\left(t_{2}\right)$ and test $\left(t_{3}\right)$ of sample $G$. 


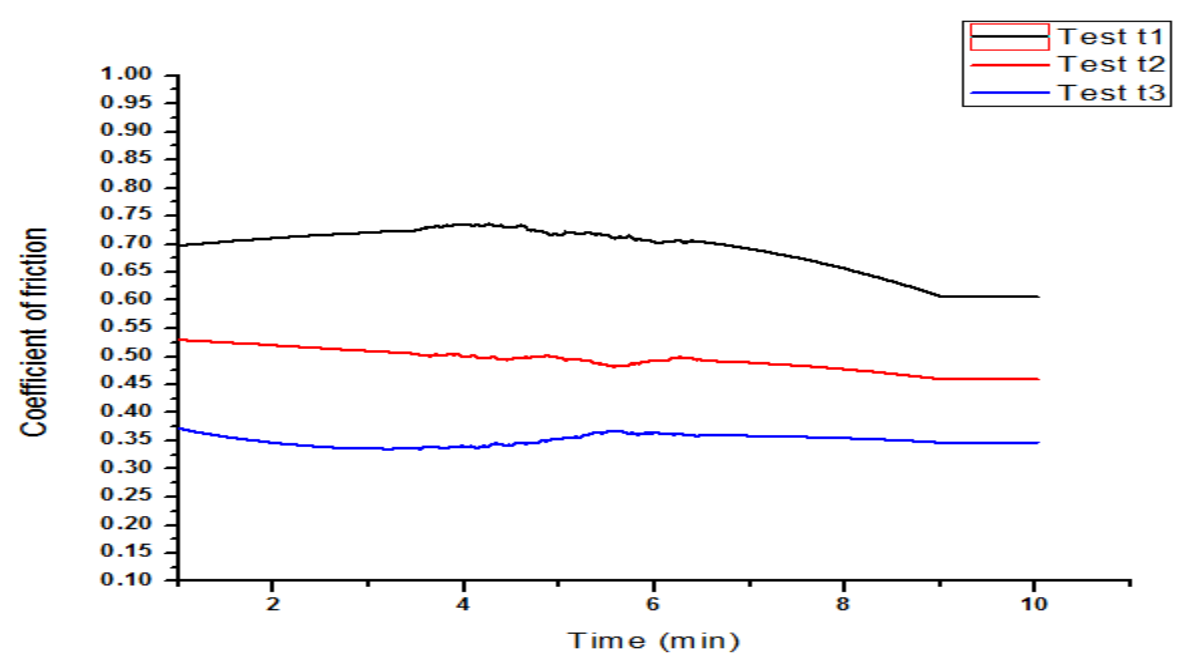

Fig.-10: Coefficient of friction for test $\left(t_{1}\right)$, test $\left(t_{2}\right)$ and test $\left(t_{3}\right)$ of sample $H$.

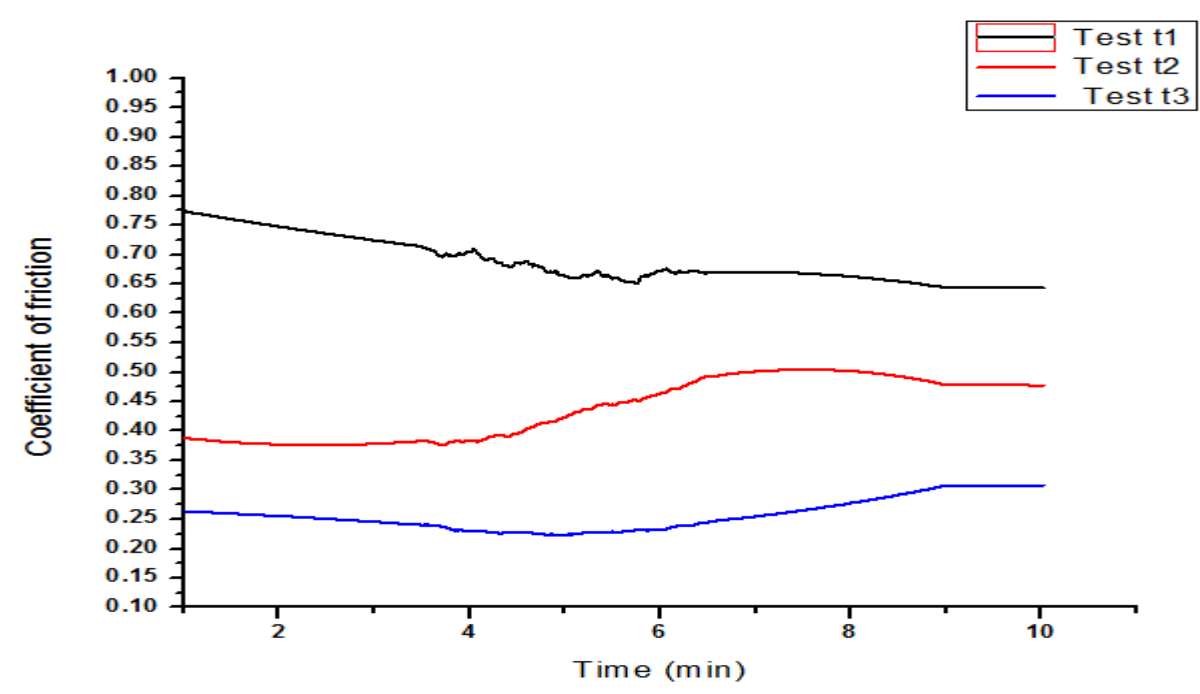

Fig.-11: Coefficient of friction for test $\left(t_{1}\right)$, test $\left(t_{2}\right)$ and test $\left(t_{3}\right)$ of sample I.

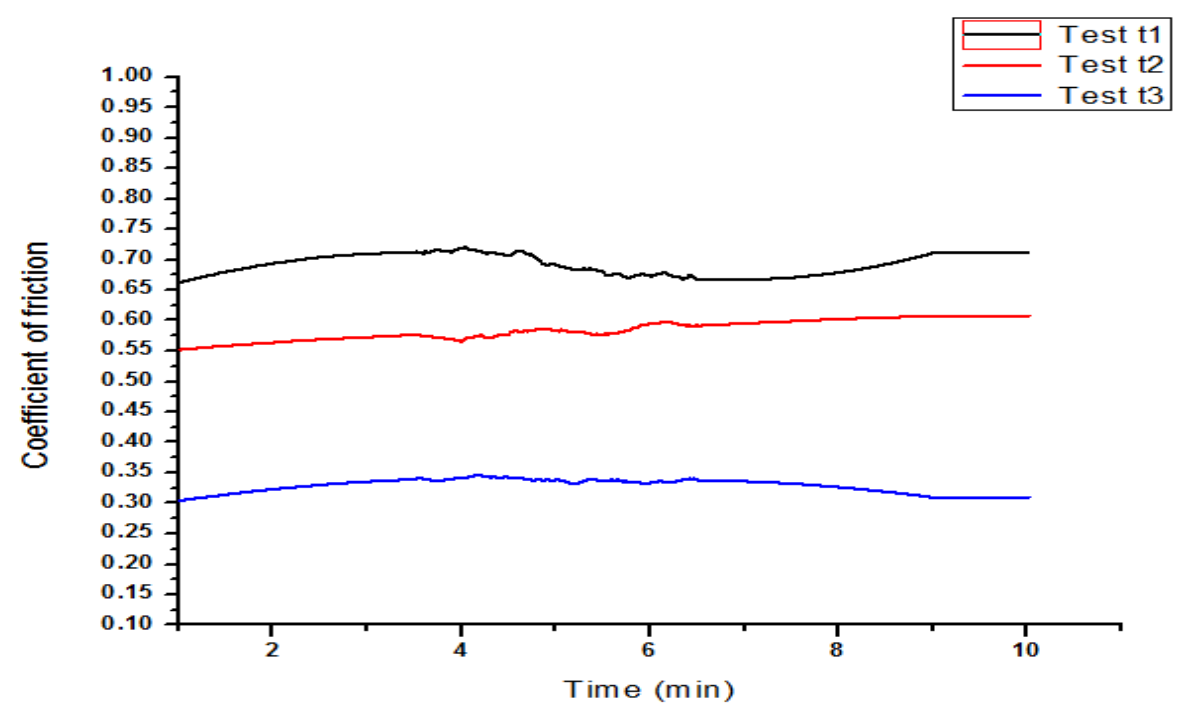


Fig.-12: Coefficient of friction for test $\left(t_{1}\right)$, test $\left(t_{2}\right)$ and test $\left(t_{3}\right)$ of sample $J$.

For test $\left(t_{1}\right)$, a rapid increase in coefficient of friction $(\mu)$ was observed with reduced wear. This increase in coefficient of friction in the samples A - $\mathbf{J}$ is attributed to the presence of steel fiber. During the initial friction test, the disc and brake pad sample rubbed with counter surface together generating a resultant coefficient of friction. Nevertheless, the abrasive modes were completely different when they came in direct contact with steel fibers.

For test $\left(\mathrm{t}_{2}\right)$, the friction coefficient values show a slight discontinuity with the sliding distance as the load and temperature increases for sample A-J. Besides, the fibers were found to be more agglomerated and their contribution was no longer considered. Raidh et al. [11] suggested that in the case of $1.0 \mathrm{wt} \%$ graphite reinforced brake pad, insufficient lubrication and the lack of the formation of tribo-oxide layer resulted in the increase in the friction coefficient values. This behavior may be ascribed to the formation of stable transfer film during sliding distances.

For test $\left(t_{3}\right)$, increase in the value of coefficient of friction was observed when the braking conditions were increased. This behavior may be ascribed to prevention of formation of film from resin residues. At higher temperature, there is the breakdown of brake efficiency which is termed as brake fade. The possible reason for brake fade is the degredation of phenolic resin [12]. However, it is observed that with increase in temperature the binding ability of the resin has been retained due to the presence of the banana peel powder and a higher coefficient of friction has been attained.

Table-3: Brake pad samples test result data.

\begin{tabular}{|c|c|c|c|c|c|c|}
\hline Sample & Test & Load $(\mathrm{N})$ & Temperature $\left({ }^{0} \mathrm{C}\right)$ & Coefficient of friction $(\mu)$ & Frictional force $(\mathrm{N})$ & Wear $(g)$ \\
\hline \multirow{3}{*}{ A } & $\mathrm{t}_{1}$ & 60 & 150 & 0.636 & 12.74 & 0.003 \\
\hline & $\mathrm{t}_{2}$ & 120 & 250 & 0.377 & 15.11 & 0.075 \\
\hline & $\mathrm{t}_{3}$ & 180 & 350 & 0.210 & 11.13 & 0.126 \\
\hline \multirow{3}{*}{$\mathrm{B}$} & $\mathrm{t}_{1}$ & 60 & 150 & 0.660 & 13.21 & 0.009 \\
\hline & $\mathrm{t}_{2}$ & 120 & 250 & 0.499 & 14.99 & 0.017 \\
\hline & $t_{3}$ & 180 & 350 & 0.314 & 12.56 & 0.038 \\
\hline \multirow{3}{*}{$\mathrm{C}$} & $\mathrm{t}_{1}$ & 60 & 150 & 0.787 & 15.75 & 0.006 \\
\hline & $t_{2}$ & 120 & 250 & 0.425 & 13.55 & 0.064 \\
\hline & $\mathrm{t}_{3}$ & 180 & 350 & 0.349 & 13.95 & 0.072 \\
\hline \multirow{3}{*}{$\mathrm{D}$} & $\mathrm{t}_{1}$ & 60 & 150 & 0.738 & 14.76 & 0.086 \\
\hline & $\mathrm{t}_{2}$ & 120 & 250 & 0.478 & 13.59 & 0.094 \\
\hline & $t_{3}$ & 180 & 350 & 0.319 & 12.76 & 0.177 \\
\hline \multirow{3}{*}{$\mathrm{E}$} & $\mathrm{t}_{1}$ & 60 & 150 & 0.753 & 15.05 & 0.010 \\
\hline & $\mathrm{t}_{2}$ & 120 & 250 & 0.479 & 14.37 & 0.065 \\
\hline & $t_{3}$ & 180 & 350 & 0.346 & 13.88 & 0.125 \\
\hline \multirow{3}{*}{$\mathrm{F}$} & $\mathrm{t}_{1}$ & 60 & 150 & 0.753 & 14.80 & 0.016 \\
\hline & $\mathrm{t}_{2}$ & 120 & 250 & 0.442 & 13.27 & 0.078 \\
\hline & $\mathrm{t}_{3}$ & 180 & 350 & 0.324 & 12.95 & 0.086 \\
\hline \multirow{3}{*}{$\mathrm{G}$} & $\mathrm{t}_{1}$ & 60 & 150 & 0.664 & 13.29 & 0.013 \\
\hline & $t_{2}$ & 120 & 250 & 0.524 & 14.77 & 0.033 \\
\hline & $\mathrm{t}_{3}$ & 180 & 350 & 0.390 & 15.61 & 0.038 \\
\hline \multirow{3}{*}{$\mathrm{H}$} & $\mathrm{t}_{1}$ & 60 & 150 & 0.712 & 14.01 & 0.034 \\
\hline & $\mathrm{t}_{2}$ & 120 & 250 & 0.536 & 14.91 & 0.073 \\
\hline & $t_{3}$ & 180 & 350 & 0.352 & 14.08 & 0.164 \\
\hline \multirow{3}{*}{ I } & $\mathrm{t}_{1}$ & 60 & 150 & 0.695 & 13.04 & 0.047 \\
\hline & $t_{2}$ & 120 & 250 & 0.434 & 13.74 & 0.061 \\
\hline & $\mathrm{t}_{3}$ & 180 & 350 & 0.279 & 12.58 & 0.067 \\
\hline \multirow{3}{*}{$\mathbf{J}$} & $\mathrm{t}_{1}$ & 60 & 150 & 0.711 & 13.81 & 0.052 \\
\hline & $\mathrm{t}_{2}$ & 120 & 250 & 0.582 & 17.48 & 0.058 \\
\hline & $t_{3}$ & 180 & 350 & 0.331 & 13.25 & 0.064 \\
\hline
\end{tabular}


There were number of subtle differences in the behavior between the various samples. Modifications of the binder, particularly in the case of sample $G$ with coefficient of friction 0.390 for test $t_{3}$, proved effective in arresting the unwanted fade and wear behavior shown by the phenolic resin. It is the banana peel powder which is responsible for the gain in the coefficient of friction and reduction in wear at higher temperature. There was also no influence of back transfer and debonding of brake pad samples. The test result data of each sample is shown in Table 3.

\section{CONCLUSION}

In the present study, the friction and wear behavior of the newly developed brake pad material with nine different composite of banana peel and phenolic resin has been evaluated for three different conditions. The important conclusion resulted from the above study are as follows:

a) Proper bonding was achieved with the banana peel powder, which resulted in an increase in coefficient of friction.

b) During the run-in period, the highest value of coefficient of friction was 0.78 for sample $\mathrm{C}$ at low energy test $\left(t_{1}\right), 0.53$ for sample $H$ at medium energy tests $\left(t_{2}\right)$ and 0.39 for sample $G$ at high energy tests $\left(t_{3}\right)$.

c) Sample G based on $40 w t \%$ of phenolic resin and $60 \mathrm{wt} \%$ of banana peel powder proved best from the frictional point of view. It showed highest fade coefficient 0.39 and moderate wear behavior.

d) Sample I based on $20 \mathrm{wt} \%$ phenolic resin and $80 \mathrm{wt} \%$ of banana peel powder had a poor coefficient of friction of 0.279 , however it showed a moderate wear performance.

e) Sample D based on 70wt\% phenolic resin and $30 \mathrm{wt} \%$ of banana peel powder showed worst wear behavior among all the samples.

f) The result of this research indicates that banana peel powder can be effectively used to increase the binding ability of phenolic resin at higher temperatures.

\section{ACKNOWLEDGEMENTS}

The authors would like to thank the National Institute of Technology, Hazratbal, Srinagar, India for their financial support and the Mechanical Engineering Department, NIT Srinagar to carry out this work in the Tribology laboratory.

\section{REFERENCES}

[1] Blau PJ, McLaughlin JC. "effect of water films and sliding speed on the frictional behavior of truck disc brake materials" international journal of Tribology: Vol 36, 709-715, 2003.

[2] Liew KW, El-Tayeb NSM. "The effect of rotor disc material on tribo-behavior of automotive brake pad materials.” Surf Rev,625-633,2008.
[3] Eriksson Mikael, Bergman Fillip, Jacobson Staffan. “ the nature of tribological contact in automotive brakes" Wear, 26-36, 2002

[4] Bijwe J., Nidhi and Satapathy B.K., "Influence of amount of resin on fade and recovery behavior of non- asbestos organic (NAO) friction material" International journal of Wear, 1068- 1078, 2005.

[5] Lee E.H., Jung H., "Development of Banana Peel Jelly and Its Antioxidant and Textural Properties" Journal of food science, 449-455, 2010.

[6] Emaga T. H., Ronkart N., Robert C., "Characterisation of pectins extracted from banana peels(Musa AAA) under different conditions using an experimental design" Journal of food chemistry, Vol 108: 463-471, 2008.

[7] Idris U.D., V.S. Aigbodion b, *, I.J. Abubakar c, C.I. Nwoye d "Eco-friendly asbestos free brake-pad: Using banana peels" Journal of Engineering sciences, 1018-1036, 2013.

[8] Cho Min Hyung, Kim Seong Jin, Kim Dachwan, Jang Ho, "Effect of ingredients on tribological characteristics of a brake lining: an experimental study" International journal of Wear, 1682-1687, 2005.

[9] Yun Rongping, Filip Peter, Lu Yafei, "Performance and evaluation of eco-friendly brake friction materials" International journal of Tribology, 20102019, 2010.

[10] Zhang S.Y., Qu. S.G., Li. Y.Y., Chen W.P., "Two body abrasive behavior of brake pad dry sliding against interpenetrating network ceramics/Al-alloy composites" International journal of Wear, 939-945, 2010.

[11] Riadh E., Singh H, Kchaou M., "Friction characteristics of a brake friction material under different braking conditions" Journal of material and design, Vol-52: 533-540, 2013.

[12] Mutlu I., Eidogan O., Findik F., “ Production of ceramic additive automotive brake lining and investigation of its braking characteristics" International journal of Tribology, 84-92, 2005. 